\title{
Comparison of Post-Cataract Surgery Visual Outcomes and Quality of Life in Patients Bilaterally Implanted with Multifocal Intraocular Lenses
}

\author{
Suhas S. Haldipurkar • Vijay Shetty · Dhruven Shah • Tanvi Haldipurkar • \\ Priyanka Kashelkar · Zain Khatib · Prachi Sankhe · Aalapi Mane • \\ Paresh Mhatre $\cdot$ Maninder Singh Setia (D)
}

Received: October 13, 2020 / Accepted: November 7, 2020 / Published online: November 27, 2020

(c) The Author(s) 2020

\section{ABSTRACT}

Introduction: The present study compared visual outcomes in eyes with bilateral implantation of two multifocal intraocular lenses (MFIOLs)-the Eyecryl ${ }^{\mathrm{TM}}$ ACTV diffractive multifocal IOL (group 1) and AcrySof ${ }^{\circledR}$ IQ $\operatorname{ReSTOR}^{\circledR}$ multifocal IOL (group 2).

Methods: This was a prospective, two-group observational longitudinal study of 118 eyes from 59 patients conducted at Laxmi Eye Institute, Panvel, India. We evaluated the patients at 1,3 , and 6 months. We assessed visual acuity, contrast sensitivity, higher-order aberrations, reading speed, defocus curve, stereopsis, quality of life (QOL), and adverse events in these participants.

Results: The median (interquartile range) bestcorrected distance visual acuity was $0.18(0$, $0.18)$ in group 1 and $0.18(0,0.18)$ in group 2 at 1,3 , and 6 months; the difference was not statistically significant $(p=0.48)$. The binocular defocus curve in both groups showed two peaks at 0.0 to $-0.5 \mathrm{D}$ and at $-2.5 \mathrm{D}$. The mean $(95 \%$ confidence interval) critical print size was significantly different between groups 1 and 2 at low illumination $(0.918$ [0.905, 0.931] vs 1.154
[1.128, 1.180]; $p=0.004)$. Contrast sensitivity was significantly better in group 1 under mesopic conditions but not under scotopic conditions. Though total QOL did not differ significantly between groups, the psychosocial quality of life was significantly better in group 1 . About $23 \%$ of patients in group 2 reported unwanted images, compared with $0 \%$ in group $1(p=0.01)$.

Conclusion: We found that the Eyecryl and AcrySof groups were comparable for best-corrected visual acuity, photopic contrast sensitivity, defocus curve, reading parameters, stereopsis, and quality of vision. However, the Eyecryl group had better mesopic contrast and a lower proportion of unwanted images. Psychosocial quality of life was significantly better in the Eyecryl group; however, satisfaction was similar between groups. The cost of one of the lenses is less than the other. Thus, individuals with limited resources may opt for the Eyecryl $^{\mathrm{TM}}$ ACTV, with similar visual outcomes.

Keywords: Multifocal IOLs; Quality of life; Reading ability; Visual acuity; Visual satisfaction
S. S. Haldipurkar · V. Shetty · D. Shah .

T. Haldipurkar · P. Kashelkar · Z. Khatib - P. Sankhe

. A. Mane - P. Mhatre · M. S. Setia ( $\square)$

Laxmi Eye Institute, Panvel, Maharashtra, India

e-mail: maninder.setia@karanamconsultancy.in 


\section{Key Summary Points}

AcrySof $^{\circledR}$ IQ ReSTOR ${ }^{\circledR}$ Multifocal IOL (Alcon Laboratories, Inc.) with low add power has a balanced design without prioritizing any foci.

Contrast sensitivity is decreased in multifocal IOLs (MFIOLs) due to distribution of light energy between different focal points.

Multifocal IOL patients experience dysphotopic phenomena of unwanted images, halos, streaks, or starbursts of light.

The Eyecryl ACTV diffractive multifocal IOL (Biotech Vision Care Pvt Ltd.) has comparable visual outcomes in terms of far, intermediate, and near visual acuity.

Defocus curves of Eyecryl ACTV diffractive and AcrySof ${ }^{\circledR}$ IQ ReSTOR ${ }^{\circledR}$ multifocal IOL confirm that MFIOLs with lower near adds have better intermediate visual acuity.

The Eyecryl ACTV diffractive multifocal IOL has comparable photopic and better mesopic contrast sensitivity than the AcrySof $^{\circledR}$ IQ ReSTOR ${ }^{\circledR}$ multifocal IOL.

In general, reading speed parameters are not different between MFIOLs.

The Eyecryl ACTV diffractive multifocal IOL group had higher psychosocial satisfaction; overall satisfaction did not differ significantly between groups.

No unwanted photopic phenomena were noted in the Eyecryl ACTV diffractive multifocal IOL group.

Individuals with limited resources (particularly in low- and low-middleincome countries) may opt for Eyecryl ${ }^{\mathrm{TM}}$ ACTV for similar visual outcomes.

\section{DIGITAL FEATURES}

This article is published with digital features, including a summary slide, to facilitate understanding of the article. To view digital features for this article go to https://doi.org/10.6084/ m9.figshare.13194713.

\section{INTRODUCTION}

Improvements in cataract surgery techniques and the introduction of new-generation intraocular lenses (IOLs) have improved postsurgical unaided visual outcomes. In addition, patients expect spectacle-free vision after cataract surgery. Monofocal IOLs can provide adequate visual acuity only at a fixed distancegenerally targeted to improve unaided distance vision. In this scenario, patients may require additional spectacles for activities requiring good intermediate or near vision [1].

In patients with bilateral cataracts, the surgeon may select one IOL for distance and another IOL for near vision-monovision. However, this choice does not allow bilateral stimulation of the visual cortex; thus, the patient loses the binocular advantage [2]. Because it is difficult to evaluate the acceptability of monovision pre-operatively due to the presence of cataract, it may not be possible to predict visual satisfaction post-surgery. Therefore, this may not be the procedure of choice in bilateral cataract surgeries.

To overcome these concerns, multifocal IOLs (MFIOLs) are an effective method to re-establish pseudo-accommodation after cataract surgery. Because of the multiple foci, these IOLs provide adequate vision for activities at multiple distances [3-5]. However, they are also associated with undesirable effects such as glare, halos, and reduced contrast sensitivity. The design of most commercially available MFIOLs may increase the spherical aberration of the eye; thus, the overall retinal image quality and quality of vision can be compromised [6]. Traditional MFIOLs may be a 'mixed bag' in cataract surgery. However, a new MFIOL, the AcrySof ${ }^{\circledR}$ IQ $\operatorname{ReSTOR}^{\circledR}$ multifocal IOL (Alcon Laboratories, Inc.), has a balanced design, without 
prioritizing any foci. This is achieved by apodization-gradual reduction of the height of the diffractive steps from the centre to the periphery and inclusion of a combination of diffractive-refractive design. Another MFIOL, the Eyecryl ${ }^{\mathrm{TM}}$ ACTV diffractive multifocal IOL (Biotech Vision Care Pvt Ltd.), is designed to prioritize distance and near vision over intermediate vision. In addition, the image clarity increases with negative aberrations; the negative spherical aberration induced by the lens compensates for the positive spherical aberration of the cornea.

In addition to good vision, it is important that optimal reading ability is achieved with MFIOL implantation. This can be assessed by reading acuity, reading speed, and contrast sensitivity-features that are important in one's ability to read adequately. Finally, all these visual outcomes should be able to improve the quality of life in these patients. With this background, this study aimed to compare the vision, reading ability, and quality of life in patients bilaterally implanted with two different types of MFIOLs (group 1: Eyecryl ${ }^{\mathrm{TM}}$ ACTV and group 2: AcrySof $^{\circledR}$ IQ ReSTOR ${ }^{\circledR}$ ).

\section{METHODS}

This is a prospective, two-group comparison longitudinal study of 118 eyes from 59 patients conducted at the Laxmi Eye Institute, Panvel, Maharashtra, India.

\section{Study Participants}

Consecutive consenting patients scheduled for cataract surgery were enrolled in the study and followed up for 6 months. The inclusion criteria were as follows: age greater than 18 years; regular corneal topography; pre-operative and post-operative corneal astigmatism of $\leq 0.75 \mathrm{D}$, and clear intraocular media; availability, willingness, and sufficient cognitive awareness to comply with examination procedures; and written informed consent for participation in the study. The exclusion criteria were as follows: pupil size $>5 \mathrm{~mm}$ scotopic size; best-corrected vision less than 6/9 and/or N/6; previous ocular surgery; ocular pathologies such as diabetic retinopathy, macular degeneration, glaucoma with field defects, or irregular corneal astigmatism; subjects who were professional pilots or truck/car drivers. Since we wanted to implant the IOLs bilaterally, the patients were enrolled only after both eyes fulfilled the inclusion criteria and had no exclusion criteria.

Patients who chose either of these MFIOLs were included in the study. The lenses were not assigned; rather the patients chose the lens based on their personal preference after the properties of lenses were explained to them by the counsellor. One MFIOL (group 2) is an apodized, diffractive single piece, foldable, hydrophobic acrylic, posterior-chamber IOL. This IOL has a $3.6 \mathrm{~mm}$ apodized central part and nine diffractive concentric zones on the anterior surface; these features provide one optical power for distance vision and a separate power for near vision. The add power of this MFIOL is $+3.0 \mathrm{D}$ at the lens plane, which provides about $2.5 \mathrm{D}$ of add power at the spectacle plane. The recent advances in apodization technology ensure a gradual reduction in the height of diffractive steps from the centre to the periphery of the lens; this creates a smooth transition of light at various focal points, i.e. distance, intermediate, and near $[4,5,7,8]$.

The other MFIOL (group 1) is a single piece, natural yellow, with a central refractive zone and a diffractive zone surrounding it, followed by a peripheral refractive area. The IOL has a series of nine concentric rings with diffractive steps on the anterior surface of the lens, and the spacing between the steps reduces progressively from the centre to the periphery. The add power of this MFIOL is +3.0 D at the IOL plane, which provides about $2.4 \mathrm{D}$ of add power at the spectacle plane [9]. The properties of both these MFIOLs are presented in Table 1.

\section{Study Procedures}

The cataract surgery was performed by smallincision phacoemulsification with IOL implantation by the same surgeon. We created a clear corneal tunnel $2.8 \mathrm{~mm}$ in size with a curvilinear capsulorhexis. After phacoemulsification and 
Table 1 The properties of the two IOLs included in the present study

\begin{tabular}{|c|c|c|}
\hline Name & Eyecryl $^{\mathrm{TM}}$ ACTV & AcrySof $^{\circledR}$ IQ ReSTOR ${ }^{\circledR}$ \\
\hline Optics & Diffractive-refractive & Diffractive-refractive \\
\hline Material & $\begin{array}{l}\text { Hydrophobic acrylic containing natural } \\
\text { chromophore }\end{array}$ & $\begin{array}{l}\text { Hydrophobic acrylic containing natural } \\
\text { chromophore }\end{array}$ \\
\hline $\begin{array}{l}\text { No. of diffractive } \\
\text { rings }\end{array}$ & 9 & 9 \\
\hline Apodization & Present & Present \\
\hline Near add & $+3.00 \mathrm{D}$ & $+3.00 \mathrm{D}$ \\
\hline Dioptric range & $+7.5 \mathrm{D}$ to $+30 \mathrm{D}$ (in $+0.5 \mathrm{D}$ steps) & $\begin{array}{l}+6 \mathrm{D} \text { to }+30 \mathrm{D} \text { (in } 0.5 \mathrm{D} \text { steps }) \\
+30 \mathrm{D} \text { to }+34 \mathrm{D} \text { (in }+1 \mathrm{D} \text { steps })\end{array}$ \\
\hline Edge design & $360^{\circ}$; Square edge & $360^{\circ}$; square edge \\
\hline A constant & 118.5 & 118.9 \\
\hline Refractive index & 1.48 & 1.55 \\
\hline Optic diameter & $6 \mathrm{~mm}$ & $6 \mathrm{~mm}$ \\
\hline Overall diameter & $13 \mathrm{~mm}$ & $13 \mathrm{~mm}$ \\
\hline
\end{tabular}

automated irrigation/aspiration of the cortical remnants, we implanted the IOL in the capsular bag and sealed the incision wound by hydration without the help of a suture. The post-operative treatment consisted of topical moxifloxacin hydrochloride $0.5 \%$ eye drops four times a day for 10 days and prednisolone acetate $1 \%$ eye drops six times daily, with weekly tapering. All cataract surgeries were uneventful.

All patients were followed at 1, 3, and 6 months. The two primary outcome measures were (1) visual acuity [uncorrected-distance, intermediate and near, best-corrected distance visual acuity (BCDVA), and distance-corrected near visual acuity (DCNVA)] using the logMAR scale; (2) contrast sensitivity measured binocularly with distance correction under photopic (85 candelas $[\mathrm{cd}] / \mathrm{m}^{2}$ ) and mesopic $\left(3 \mathrm{~cd} / \mathrm{m}^{2}\right)$ conditions on a Pelli-Robson chart at a distance of $1 \mathrm{~m}$. The secondary outcomes were as follows: (1) Higher-order aberrations (HOA) such as coma, spherical, trefoil, and secondary astigmatism were measured for internal, corneal, and total values at 2 and $4 \mathrm{~mm}$ pupil size to simulate photopic and mesopic conditions using the HOYA iTrace ray-tracing system
(Tracey Technologies, Houston, TX, USA). (2) Reading speed was measured using the MNREAD chart in two illuminations, i.e. $>100 \mathrm{~lx}$ and $<100 \mathrm{~lx}$. (3) Defocus curves for each MFIOL were obtained by plotting the mean of visual acuity with 13 values of defocus from $+2.0 \mathrm{D}$ to $-4.0 \mathrm{D}$ on the ETDRS chart in $\log$ MAR units. The defocus curve simulates the patient's binocular visual acuity at different distances by placing positive and negative lenses in $0.5 \mathrm{D}$ increments in front of the patient's eyes. The measurements were performed by adding the lenses to the BCDVA. (4) Stereopsis in arc seconds was assessed by the Titmus Stereo Fly test, which measures how minutely the two eyes can discern differences in the distance of objects from the observer.

We also assessed visual quality of life (QOL) using the 33-item Indian Vision Functioning Questionnaire (IND-VFQ-33) at 3 months. The VFQ-33 has a total of 33 questions divided into three categories-general, psychosocial, and visual [10]. A score is given to each answer, and a higher score indicates poorer QOL. We also asked questions regarding patient experience of unwanted images, satisfaction with vision, and 
disappointment due to unwanted images $[11,12]$. Finally, we recorded any side effects or complications over this 6-month period.

\section{Statistical Methods}

Data were entered in Stata version 15 software (StataCorp LLC, College Station, TX, USA). We estimated the means and standard deviations (SD), and median and interquartile range (IQR) for continuous variables. The normality of the data was assessed by the Shapiro-Wilk test. We estimated the proportions for categorical variables. The means were compared using the $t$ test and the medians were compared using the Mann-Whitney test. The proportions were compared using the chi-square test or Fisher's exact test for low expected cell counts. To account for changes in illumination, we adjusted the means for illumination values. We had a power of more than $80 \%$ to detect a difference of 0.06 units (in logMAR values) between these two groups (with an alpha value of 0.05 ). A $p$ value of $<0.05$ was considered statistically significant. The study was approved by the Institutional Ethics Committee at Laxmi Eye Institute and Laxmi Charitable Trust ECR/578/ Inst/MH/2014/RR-17; LEI/001/2017. The study was conducted according to the principles of the Declaration of Helsinki of 1964, and all participants signed an informed consent form.

\section{RESULTS}

Of these 59 patients, 29 (58 eyes) were in group 1 and 30 (60 eyes) were in group 2. The mean age (SD) was 59.5 (8.7) years in group 1 and 62.1 (6.1) years in group 2; the difference was not statistically significant $(p=0.21)$. There was no significant difference in the proportion of men and women in these groups (men: 48\% [ $n=14]$ vs $30 \%$ [ $n=9]$; women: $52 \%[n=15]$ vs $70 \%$ $[n=21])(p=0.15)$. There were also no significant differences in the median BCDVA $(0.18$ $[0.18,0.48]$ vs $0.18[0.18,0.24] ; p=0.42)$, spherical error $(0[-2.5,1.5]$ vs $-0.75[-2.0$, $1.5] ; p=0.71)$, or cylindrical error $(0[-0.75,0]$ vs $0[-1.0,0] ; p=0.98)$ at baseline between groups 1 and 2 (values in respective order).
Table 2 Baseline characteristics of participants in both IOL groups included in the present study

\begin{tabular}{llll}
\hline Characteristics & Group 1 & Group 2 & $\boldsymbol{p}$ value \\
\hline Age $[\text { mean }(\mathrm{SD})]^{\mathrm{a}}$ & $\begin{array}{c}59.6 \\
( \pm 8.7)\end{array}$ & $\begin{array}{c}62.1 \\
( \pm 6.1)\end{array}$ & 0.07 \\
& & & \\
Gender $[n(\%)]^{\mathrm{a}}$ & & & \\
Male & $14(48 \%)$ & $15(52 \%)$ & 0.15 \\
Female & $9(30 \%)$ & $21(70 \%)$ & \\
BCDVA logMAR & $0.18(0.18$, & $0.18(0.18$, & 0.42 \\
{$[$ median (IQR) $]$} & $0.48)$ & $0.24)$ & \\
Spherical error D & $0.0(-2.5$, & -0.75 & 0.71 \\
[median (IQR)] & $1.5)$ & $(-2.0$, & \\
& & $1.5)$ & \\
Cylindrical error D & 0.0 & $0.0(-1.0$, & 0.98 \\
{$[$ median (IQR) $]$} & $(-0.75$, & $0.0)$ & \\
& $0.0)$ & &
\end{tabular}

${ }^{a}$ Age and gender were based on the total number of individuals

There were no significant differences in the demographic or visual parameters at baseline (Table 2).

\section{Vision and Higher-Order Aberrations}

The median (IQR) uncorrected distance vision at 1 month was $0.18(0.0,0.18)$ in group 1 and $0.18(0.18,0.18)$ in group $2(p=0.38)$. The median (IQR) BCDVA was $0.18(0,0.18)$ in group 1 and $0.18(0,0.18)$ in group 2 at 1,3 , and 6 months; the difference was not statistically significant $(p=0.48)$. The median (IQR) DCNVA was $0.18(0.18,0.18)$ in group 1 and $0.18(0.18,0.18)$ in group $2(p=0.05)$ at all three visits. Finally, the median (IQR) distancecorrected intermediate visual acuity (DCIVA) was $0.40(0.30,0.40)$ in group 1 and $0.40(0.30$, 0.48 ) in group 2 at 1 month. Even though the difference was statistically significant $(p=0.01)$, it was not clinically significant (considered as two-line/10 letter-gain). In general, there were no significant differences in HOAs (internal, 


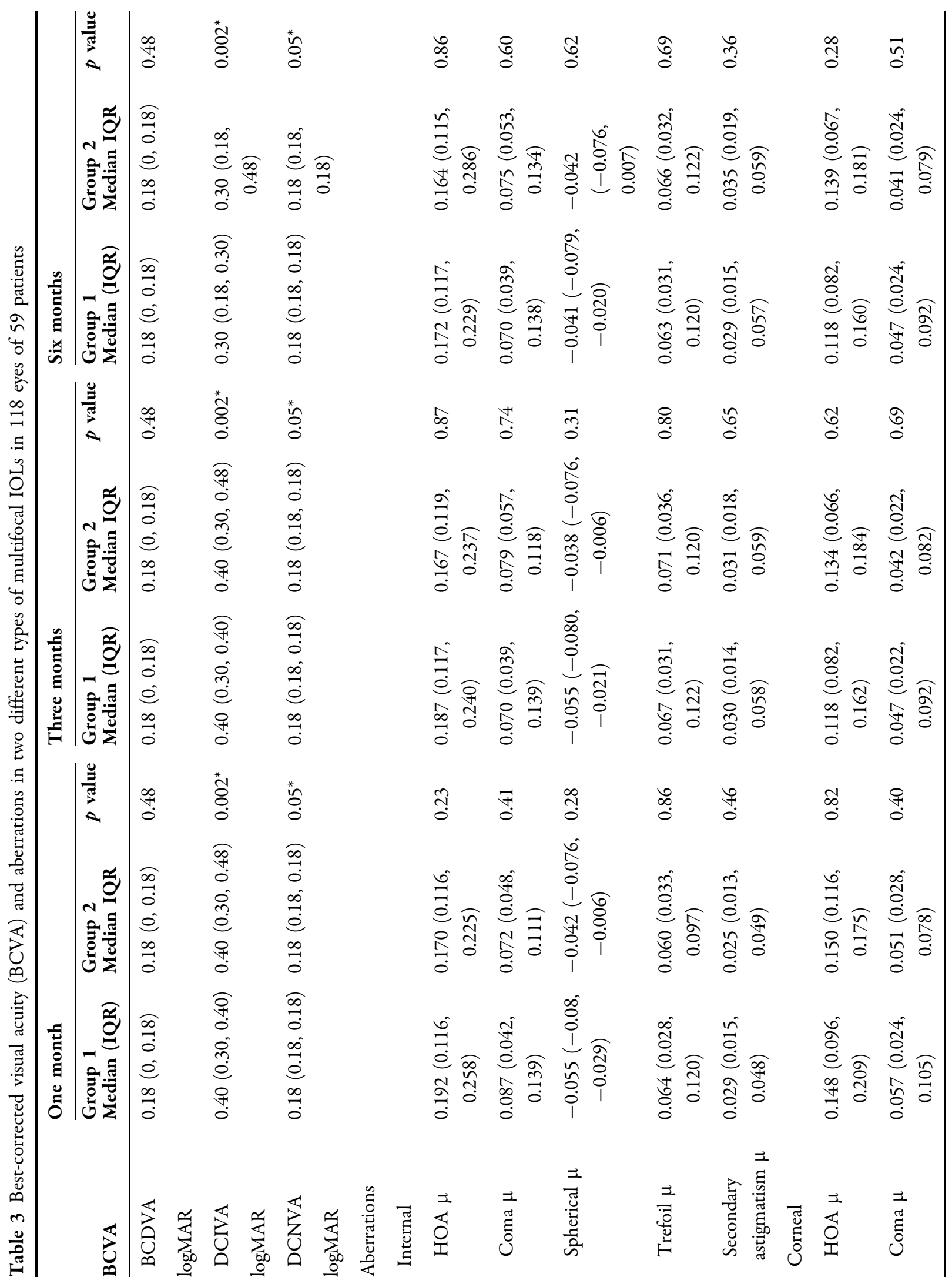




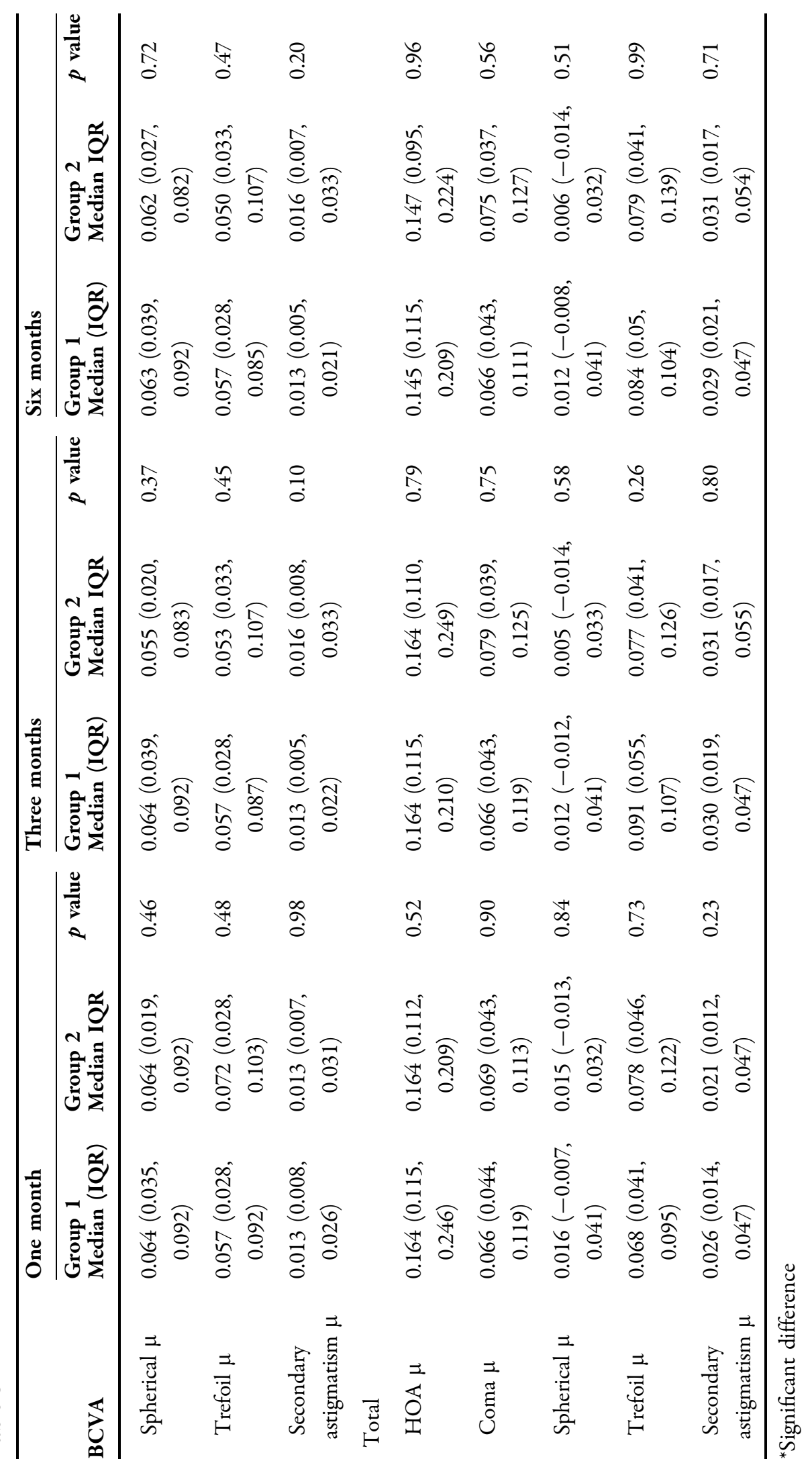




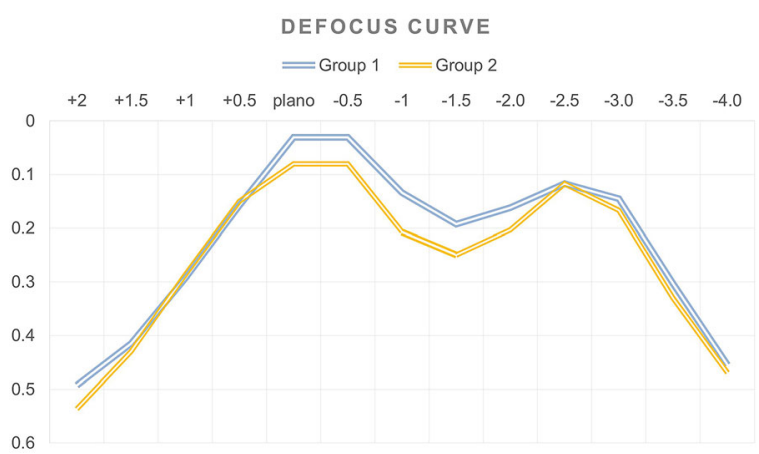

Fig. 1 Defocus curves in the 59 patients in the Eyecryl and AcrySof groups

corneal, and total). We present detailed analyses of vision and HOAs in Table 3.

\section{Defocus Curve}

The binocular defocus curve in both MFIOL groups showed two peaks at 0.0 to $-0.5 \mathrm{D}$ $(6-2 \mathrm{~m})$ and at $-2.5 \mathrm{D}$ (maximum near visual acuity at $40 \mathrm{~cm}$ ). The visual acuity for intermediate distance was better than that for distance and near vision. The mean (SD) visual acuity at $0.0 \mathrm{D}$ was $0.031(0.060)$ in group 1 and 0.080 (0.096) in group $2(p=0.02)$; at $-1.0 \mathrm{D}$ it was $0.13(0.018)$ in group 1 and $0.20(0.023)$ in group $2(p=0.02)$; and at $-1.5 \mathrm{D}$ it was 0.19 (0.015) in group 1 and $0.25(0.019)$ in group 2 $(p=0.03)$. At these three distances, the difference in the means was statistically significant; group 1 was marginally better than group 2 . Defocus curve analyses are show in Fig. 1. As seen in the figure, the defocus curve was slightly better in group 1 than group 2 for distance and intermediate range, with similar results for near range. Thus, group 1 performed better than group 2 for distance and near vision.

\section{Other Parameters}

The analyses were conducted in a subgroup of individuals. We analysed 11 participants in group 1 and 13 in group 2 for reading speed parameters. After adjusting for illumination, in general, there were no significant differences between these lenses (Table 4). However, the mean (95\% confidence interval) critical print

Table 4 Contrast sensitivity, stereopsis, and reading speed parameters in 59 patients

\begin{tabular}{llll}
\hline & $\begin{array}{l}\text { Group 1 } \\
\text { Mean }(\underline{ \pm} \text { SD) }\end{array}$ & $\begin{array}{l}\text { Group 2 } \\
\text { Mean }( \pm \text { SD) }\end{array}$ & $p$ value \\
\hline Contrast sensitivity (log CS) & $1.422(0.142)$ & $1.335(0.127)$ & $0.02^{*}$ \\
Mesopic & $1.493(0.112)$ & $1.511(0.105)$ & 0.51 \\
Photopic & $87.18(35.45)$ & $98.60(74.53)$ & 0.46 \\
Stereopsis (arc secs) & & & \\
Reading speed parameters (words per minute-wpm), & & 0.54 \\
median (IQR) & $178.32(177.13,179.51)$ & $164.24(161.90,166.59)$ & 0.29 \\
Reading speed in low illumination & $149.26(145.54,152.97)$ & $173.03(169.74,176.32)$ & 0.08 \\
Reading speed in high illumination & $0.237(0.212,0.263)$ & $0.311(0.261,3.610)$ & 0.72 \\
Reading acuity in low illumination & $0.207(0.187,0.228)$ & $0.251(0.233,0.269)$ & $0.004^{*}$ \\
Reading acuity in high illumination & $0.918(0.905,0.931)$ & $1.154(1.128,1.180)$ & 0.13 \\
Critical print size in low illumination & $1.009(0.993,1.026)$ & $1.177(1.162,1.192)$ & \\
Critical print size in high illumination & & & \\
\hline
\end{tabular}

*Significant difference 


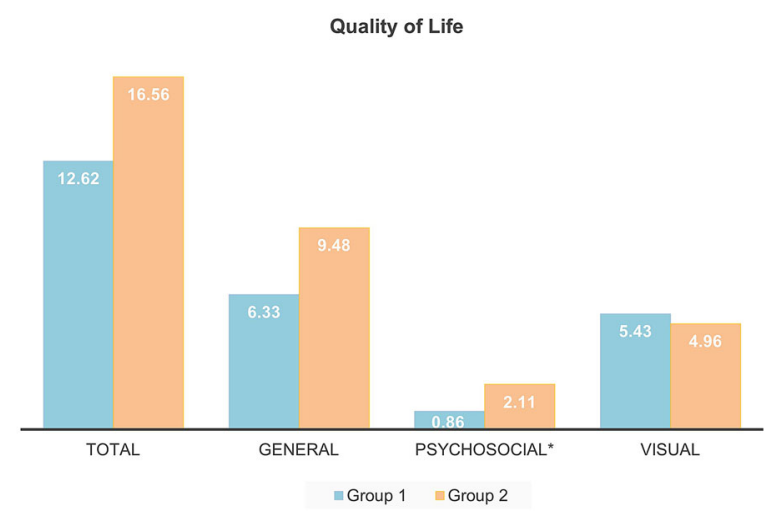

Fig. 2 Figure showing the mean quality of life in two different types of multifocal IOLs (Eyecryl and AcrySof). ${ }^{*} p<0.05$

size was significantly different between groups 1 and 2 at low illumination $(0.918$ [0.905, 0.931] vs 1.154 [1.128, 1.180]; $p=0.004)$, but not at high illumination $(1.009$ [0.993, 1.026] vs 1.177 $[1.162,1.192] ; p=0.13)$.

The mean (SD) contrast sensitivity was significantly better in group 1 than in group 2 under mesopic conditions (1.422 [0.142] vs 1.335 [0.127]; $p=0.02$ ), but not under scotopic conditions (1.493 [0.112] vs 1.511 [0.105]; $p=0.51$ ). Stereopsis did not differ significantly between groups. Additional analyses for the above-mentioned parameters are shown in Table 4.

\section{Quality of Life}

A total of 48 patients (21 from group 1 and 27 from group 2) responded to the quality of life questionnaire (IND-VFQ-33). The mean (SD) total QOL was not significantly different between groups (12.62 [6.92] vs 16.56 [13.08]; $p=0.22$ ). Similarly, the general and visual QOL did not differ significantly between these groups (Fig. 2). However, the psychosocial quality of life was significantly better in group 1 than in group 2 (0.86 [1.28] vs 2.11 [1.78]; $p=0.009)$.

A total of 58 patients ( 28 in group 1 and 30 in group 2) responded to the questions on unwanted images and satisfaction with vision. About $23 \%(n=7)$ of patients in group 2 reported unwanted images, compared with $0 \%$ $(n=0)$ in group $1(p=0.01)$, and $30 \%(n=9)$ of the patients in group 2 attributed their disappointment with their current vision to unwanted images $(0 \% \quad[n=0] \quad$ vs $30 \% \quad[n=9]$; $p=0.002)$. In general, however, there were no significant differences in the level of satisfaction between groups: extremely satisfied (43\% $[n=12]$ vs $43 \%[n=13])$ and satisfied $(57 \%$ $[n=16]$ vs $57 \%[n=17])(p=0.97)$.

We did not record any complications such as inflammation or corneal edema in any patient at the 6-month visit.

\section{DISCUSSION}

Our study provides a mixed picture on the differences in these MFIOLs. Some of the visual acuity parameters were better in group 2 than in group 1 (though statistically significant, not necessarily clinically significant). However, the contrast sensitivity under mesopic conditions was better in group 1 than in group 2. Furthermore, even though there was no significant difference in the total quality of life, the psychosocial quality of life was significantly better in group 1 than in group 2. A higher proportion of individuals in group 2 reported unwanted images. Satisfaction with the IOLs did not differ significantly between groups.

MFIOLs are designed to provide functional distance and near vision after cataract surgery. Multiple theoretical and clinical studies have previously shown that diffractive MFIOLs are superior to refractive lenses for near vision, whereas for distance vision, the two were found to be comparable [2, 13-17]. However, in today's world, the need for intermediate vision has gained importance due to an increase in the use of computers and other instruments. To meet this growing demand for unaided distance, intermediate, and near vision by presbyopic patients, along with good quality of vision, numerous improvements have been and continue to be made in the optical design of MFIOLs [18]. It is important to follow certain basic principles to maximize patient outcomes with MFIOLs, such as careful selection of patients, proper education and counselling of 
patients, and discussion of the benefits and side effects of each type of MFIOL [19].

We analysed the post-operative results at months 1,3 , and 6 to allow adequate time for the brain to adapt to the newer MFIOL optical system. Though the best-corrected distance visual acuity was comparable between groups, distance-corrected near visual acuity was better in group 2, and distance-corrected intermediate visual acuity was better in group 1, although these differences were not necessarily clinically significant (considered as two-line/10-letter gain [20]). Overall, the uncorrected and bestcorrected visual acuity was good in both groups. In our study, near visual acuity was measured at $40 \mathrm{~cm}$, which is more physiologic in terms of actual lifestyle than a $33 \mathrm{~cm}$ location of near focus. Thus, patients with $+3.00 \mathrm{D}$ aspheric IOLs had better results [21]. To improve visual acuity at intermediate distances, MFIOLs with low add have been designed to increase the range of focus [22-25]. Our results for intermediate visual acuity are similar to those reported by other authors [17].

Unlike monofocal IOLs, where all light energy is available for a single focal point, in MFIOLs, contrast sensitivity is reduced because of the distribution of available light energy between two or more focal points. Thus, the near retinal image may have reduced contrast compared with the distance image [26-28]. It has been reported that patients with MFIOLs have worse contrast sensitivity under dim light conditions [1]. Other studies have found that MFIOLs had acceptable results, like monofocal IOLs, and did not reduce visual functionality $[29,30]$. The defocus curve with various additions has also been studied. Alfonso and coworkers found that a +3.00 aspheric group had better results at $-2.00 \mathrm{D}$ and $-2.50 \mathrm{D}$ vergence, which corresponds to a distance of $50 \mathrm{~cm}$ and $40 \mathrm{~cm}$, respectively [21]. In our study, both groups had good intermediate vision, with the Eyecryl group being slightly better at $-1.5 \mathrm{D}$ (approximately $66.67 \mathrm{~cm}$ ). MFIOLs have better stereopsis than monofocal IOLs [31]. Aspheric IOLs are also designed to correct spherical aberration of the cornea. Normally, corneas have positive spherical aberrations; thus, to counteract these, IOLs should have negative aberrations to provide balanced and good postoperative optical quality [32]. It is also hypothesized that the apodization of the ReSTOR IOL reduces spherical aberration in a way similar to that of an aspheric IOL [33-35]. Our study showed no difference in aberrations between the two groups. Jorge and colleagues evaluated a trifocal lens (FineVision trifocal IOL, PhysIOL, Liege, Belgium) [36], and found that the lens performed well for intermediate vision in addition to distance and near vision. There were similarities, however, in the defocus curve; it showed two peaks, with a slight dip in the intermediate vision. A study by Mojzis and coworkers evaluated another MFIOL (AT LISA tri 839MP, Carl Zeiss Meditec AG) [37]. The authors found that the lens performed well for distance, intermediate, and near vision, and the defocus curve showed a single peak, with good intermediate vision.

Apart from these outcomes, we also evaluated the reading speed and the smallest print size. Reading is an integral part of daily activity; hence, an assessment of near visual acuity alone is not enough. Reading parameters including reading speed, reading acuity, and critical print size provide a better measurement of psychophysical and objective examination [38]. After adjusting for illumination, in general, the reading parameters were comparable between groups. Group 1 reported better psychosocial quality of life, even though the total quality of life was comparable in the two groups. In general, fully diffractive IOLs may provide better quality of vision than apodized multifocal or monofocal lenses $[39,40]$. The overall satisfaction with MFIOLs was similar between the groups.

A limitation of this study was the varying number of participants across these outcomes. We could not include a large number of individuals for reading parameters due to nonavailability of standardized reading charts in some of the Indian languages. The other limitation is that this was not a randomized study, and the patients and the surgeon were aware of the type of lens used. Nonetheless, the study provides a detailed and multifaceted comparison of two types of MFIOLs. 


\section{CONCLUSION}

We found that Eyecryl and AcrySof groups were comparable for best-corrected visual acuity, photopic contrast sensitivity, defocus curve, reading parameters, stereopsis, and quality of vision. However, the Eyecryl group had better mesopic contrast and a lower proportion of unwanted images. The cost (maximum retail price) of AcrySof ${ }^{\circledR}$ IQ ReSTOR is 42,100 Indian rupees (USD 565), and the cost of Eyecryl ${ }^{\mathrm{TM}}$ ACTV is 25,000 Indian rupees (USD 336). In India, health care access is an 'out-of-pocket' expense; thus, the price of the lens is an important factor in patients' choice of lens. Even though there are newer lenses available, their cost is higher than the two compared in this study. Hence, the MFIOLs compared in this study are offered as potential options in presurgery counselling. As the cost of one of the lenses is less than the other, individuals with limited resources may opt for the Eyecryl ${ }^{\mathrm{TM}}$ ACTV for similar visual outcomes.

\section{ACKNOWLEDGEMENTS}

We would like to thank the participants of the study.

Funding. This study was funded by a research grant from Biotech Vision Care Pvt Ltd. The Rapid Service Fee was also included in this research grant.

Disclosures. Suhas S. Haldipurkar, Vijay Shetty, Dhruven Shah, Tanvi Haldipurkar, Priyanka Kashelkar, Zain Khatib, Prachi Sankhe, Aalapi Mane, Paresh Mhatre and Maninder Singh Setia have no financial or proprietary interest in a product, method, or material described herein. There are no competing interests.

Authorship. All named authors meet the International Committee of Medical Journal Editors (ICMJE) criteria for authorship for this article, take responsibility for the integrity of the work as a whole, and have given their approval for this version to be published.

Compliance with Ethics Guidelines. This study was approved by the Institutional Ethics Committee at Laxmi Eye Institute and Laxmi Charitable Trust ECR/578/Inst/MH/2014/RR-17; LEI/001/2017. The study was conducted according to the principles of the Declaration of Helsinki of 1964, and all participants signed an informed consent form.

Data Availability. The datasets generated during and/or analyzed during the current study are available from the corresponding author on reasonable request and approval by the institutional ethics committee.

Open Access. This article is licensed under a Creative Commons Attribution-NonCommercial 4.0 International License, which permits any non-commercial use, sharing, adaptation, distribution and reproduction in any medium or format, as long as you give appropriate credit to the original author(s) and the source, provide a link to the Creative Commons licence, and indicate if changes were made. The images or other third party material in this article are included in the article's Creative Commons licence, unless indicated otherwise in a credit line to the material. If material is not included in the article's Creative Commons licence and your intended use is not permitted by statutory regulation or exceeds the permitted use, you will need to obtain permission directly from the copyright holder. To view a copy of this licence, visit http://creativecommons.org/licenses/by$\mathrm{nc} / 4.0 /$.

\section{REFERENCES}

1. Montes-Mico R, Espana E, Bueno I, Charman WN, Menezo JL. Visual performance with multifocal intraocular lenses: mesopic contrast sensitivity under distance and near conditions. Ophthalmology. 2004;111(1):85-96.

2. Steinert RF, Aker BL, Trentacost DJ, Smith PJ, Tarantino N. A prospective comparative study of the AMO ARRAY zonal-progressive multifocal silicone 
intraocular lens and a monofocal intraocular lens. Ophthalmology. 1999;106(7):1243-55.

3. Javitt JC, Steinert RF. Cataract extraction with multifocal intraocular lens implantation: a multinational clinical trial evaluating clinical, functional, and quality-of-life outcomes. Ophthalmology. 2000;107(11):2040-8.

4. Kamlesh DS, Kaushik S. Contrast sensitivity and depth of focus with aspheric multifocal versus conventional monofocal intraocular lens. Can J Ophthalmol. 2001;36(4):197-201.

5. Pineda-Fernandez A, Jaramillo J, Celis V, et al. Refractive outcomes after bilateral multifocal intraocular lens implantation. J Cataract Refract Surg. 2004;30(3):685-8.

6. Barbero S, Marcos S, Jimenez-Alfaro I. Optical aberrations of intraocular lenses measured in vivo and in vitro. J Opt Soc Am A Opt Image Sci Vis. 2003;20(10):1841-51.

7. Madrid-Costa D, Cervino A, Ferrer-Blasco T, GarciaLazaro S, Montes-Mico R. Visual and optical performance with hybrid multifocal intraocular lenses. Clin Exp Optom. 2010;93(6):426-40.

8. Myalcon. AcrySof IQ ReSTOR presbyopia-correcting IOLs more options to broaden your patients' outlook. 2019. https://www.myalcon.com/ professional/cataract-surgery/intraocular-lens/ acrysof-iq-restor-multifocal-iol. Accessed Nov 19, 2019.

9. Biotech Visioncare. Eyecryl activ range optimally treating presbyopia. 2019. http://www. biotechhealthcare.com/wp-content/uploads/2019/ 04/EYECRYL-\%E2\%94\%82-ACTV-IOL-RANGE-\% E2\%94\%82-MKT1129-\%E2\%94\%82-REV03-\%E2\% 94\%82-01-03-2019.pdf. Accessed Nov 19, 2019.

10. Gupta SK, Viswanath $\mathrm{K}$, Thulasiraj RD, et al. The development of the Indian vision function questionnaire: field testing and psychometric evaluation. Br J Ophthalmol. 2005;89(5):621-7.

11. Grzybowski A, Kanclerz P, Muzyka-Wozniak M. Methods for evaluating quality of life and vision in patients undergoing lens refractive surgery. Graefes Arch Clin Exp Ophthalmol. 2019;257(6):1091-9.

12. Vyas A. Incidence of dysphotopsia in patients implanted with the C-flex ${ }^{\circledR}$ intraocular lens with $360^{\circ}$ enhanced edge: a questionnaire-based study. J Clin Exp Ophthalmol. 2015;6:1.

13. Walkow T, Liekfeld A, Anders N, Pham DT, Hartmann C, Wollensak J. A prospective evaluation of a diffractive versus a refractive designed multifocal intraocular lens. Ophthalmology. 1997;104(9): 1380-6.

14. Steinert RF. Visual outcomes with multifocal intraocular lenses. Curr Opin Ophthalmol. 2000;11(1):12-21.

15. Weghaupt $\mathrm{H}$, Pieh S, Skorpik C. Comparison of pseudoaccommodation and visual quality between a diffractive and refractive multifocal intraocular lens. J Cataract Refract Surg. 1998;24(5):663-5.

16. Pieh S, Marvan P, Lackner B, et al. Quantitative performance of bifocal and multifocal intraocular lenses in a model eye: point spread function in multifocal intraocular lenses. Arch Ophthalmol. 2002;120(1):23-8.

17. Kohnen T, Allen D, Boureau C, et al. European multicenter study of the AcrySof ReSTOR apodized diffractive intraocular lens. Ophthalmology. 2006;113(4):578-84

18. Dexl AK, Zaluski S, Rasp M, Grabner G. Visual performance after bilateral implantation of a new diffractive aspheric multifocal intraocular lens with a 3.5 D addition. Eur J Ophthalmol. 2014;24(1): $35-43$.

19. Alio JL, Grabner G, Plaza-Puche AB, et al. Postoperative bilateral reading performance with 4 intraocular lens models: six-month results. J Cataract Refract Surg. 2011;37(5):842-52.

20. Beck RW, Maguire MG, Bressler NM, Glassman AR, Lindblad AS, Ferris FL. Visual acuity as an outcome measure in clinical trials of retinal diseases. Ophthalmology. 2007;114(10):1804-9.

21. Alfonso J, Fernández-Vega L, Puchades C, MontésMicó R. Intermediate visual function with different multifocal intraocular lens models. J Cataract Refract Surg. 2010;36(5):733-9.

22. Alio JL, Elkady B, Ortiz D, Bernabeu G. Clinical outcomes and intraocular optical quality of a diffractive multifocal intraocular lens with asymmetrical light distribution. J Cataract Refract Surg. 2008;34(6):942-8.

23. Alfonso JF, Puchades C, Fernandez-Vega L, MontesMico R, Valcarcel B, Ferrer-Blasco T. Visual acuity comparison of 2 models of bifocal aspheric intraocular lenses. J Cataract Refract Surg. 2009;35(4):672-6.

24. Alfonso J, Fernández-Vega L, Valcárcel B, MontésMicó R. Visual performance after AcrySof ReSTOR aspheric intraocular lens implantation. J Optom. 2008;1(1):30-5. 
25. Alfonso JF, Fernandez-Vega L, Senaris A, MontesMico R. Prospective study of the Acri.LISA bifocal intraocular lens. J Cataract Refract Surg. 2007;33(11):1930-5.

26. Vega F, Alba-Bueno F, Millan MS. Energy distribution between distance and near images in apodized diffractive multifocal intraocular lenses. Invest Ophthalmol Vis Sci. 2011;52(8):5695-701.

27. Eppig T, Rubly K, Rawer A, Langenbucher A. Visualization of light propagation with multifocal intraocular lenses using the ouzo effect. Biomed Res Int. 2019;2019:6425040.

28. Salerno LC, Tiveron MC Jr, Alio JL. Multifocal intraocular lenses: types, outcomes, complications and how to solve them. Taiwan J Ophthalmol. 2017;7(4):179-84.

29. de Vries NE, Webers CA, Verbakel F, et al. Visual outcome and patient satisfaction after multifocal intraocular lens implantation: aspheric versus spherical design. J Cataract Refract Surg. 2010;36(11):1897-904.

30. Zhao G, Zhang J, Zhou Y, Hu L, Che C, Jiang N. Visual function after monocular implantation of apodized diffractive multifocal or single-piece monofocal intraocular lens Randomized prospective comparison. J Cataract Refract Surg. 2010;36(2):282-5.

31. Jusufovic V, Sarajlic D, Zvornicanin J, Musanovic Z, Halilbasic M. Comparison of the binocular vision quality after implantation of monofocal and multifocal intraocular lenses. Acta Med Saliniana. 2011;40(2):63-8.

32. Toto L, Falconio G, Vecchiarino L, et al. Visual performance and biocompatibility of 2 multifocal diffractive IOLs: six-month comparative study. J Cataract Refract Surg. 2007;33(8):1419-25.
33. Altmann GE. Wavefront-customized intraocular lenses. Curr Opin Ophthalmol. 2004;15(4):358-64.

34. Piers PA, Weeber HA, Artal P, Norrby S. Theoretical comparison of aberration-correcting customized and aspheric intraocular lenses. J Refract Surg. 2007;23(4):374-84.

35. de Santhiago MR, Netto MV, Barreto J Jr, Gomes Bde A, Schaefer A, Kara-Junior N. A contralateral eye study comparing apodized diffractive and full diffractive lenses: wavefront analysis and distance and near uncorrected visual acuity. Clinics (Sao Paulo). 2009;64(10):953-60.

36. Alio JL, Montalban R, Pena-Garcia P, Soria FA, VegaEstrada A. Visual outcomes of a trifocal aspheric diffractive intraocular lens with microincision cataract surgery. J Refract Surg. 2013;29(11):756-61.

37. Mojzis P, Pena-Garcia P, Liehneova I, Ziak P, Alio JL. Outcomes of a new diffractive trifocal intraocular lens. J Cataract Refract Surg. 2014;40(1):60-9.

38. Santhiago MR, Netto MV, Espindola RF, et al. Comparison of reading performance after bilateral implantation of multifocal intraocular lenses with +3.00 or +4.00 diopter addition. J Cataract Refract Surg. 2010;36(11):1874-9.

39. Khandelwal SS, Jun JJ, Mak S, Booth MS, Shekelle PG. Effectiveness of multifocal and monofocal intraocular lenses for cataract surgery and lens replacement: a systematic review and meta-analysis. Graefes Arch Clin Exp Ophthalmol. 2019;257(5):863-75.

40. Alio JL, Plaza-Puche AB, Pinero DP, Amparo F, Rodriguez-Prats JL, Ayala MJ. Quality of life evaluation after implantation of 2 multifocal intraocular lens models and a monofocal model. J Cataract Refract Surg. 2011;37(4):638-48. 